\title{
Educação, neoliberalismo e/ou sociedade administrada ${ }^{1}$
}

\section{Education, neoliberalism and/or managed society}

\author{
José Leon Crochick ${ }^{*}$
}

\begin{abstract}
RESUMO
O objetivo deste trabalho é refletir sobre as condições atuais de formação individual, considerando a atual estrutura social capitalista e a ideologia neoliberal. Para cumprir este objetivo, a exposição do texto está dividida em três partes; a primeira traz elementos para se pensar o neoliberalismo como ideologia; a segunda trata da formação individual sob a égide dessa ideologia, no tocante ao produtivismo e empreendedorismo exigidos atualmente, às características de personalidade, favoráveis ou contrárias à democracia e relacionadas com formas de violência escolar; e a última parte discorre sobre a relação do neoliberalismo e a formação do indivíduo. Defende-se que a ideologia neoliberal oculta a inexistência do mercado, auxiliando a concentrar o capital em um número de grupos cada vez menor, e a não percepção disso pode levar à defesa do estado de bem-estar social, que se permite melhores condições materiais de vida para a população, o que é importante não deixou de ser alvo de críticas, sobretudo de pensadores da Teoria Crítica da Sociedade. Para a administração desse sistema de concentração de renda é necessária uma administração de cunho fascista, ainda que possa ter aparência de democracia; se é um fenômeno objetivo, não prescinde de indivíduos que o sustentem, que sejam formados por uma relação superficial com a realidade, a qual possibilita uma expressão de violência, que indica necessidades de personalidade regredidas.
\end{abstract}

Palavras-chave: Formação do indivíduo. Crítica social. Neoliberalismo.

1 Bolsista Produtividade em Pesquisa do Conselho Nacional de Desenvolvimento Científico e Tecnológico (CNPq). Processo 306790/2018-1, a quem o autor agradece.

"Universidade Federal de São Paulo. Programa de Pós-Graduação em Educação e Saúde na infância e na adolescência. São Paulo, São Paulo, Brasil. E-mail: jlchna@usp.br https://orcid.org/0000-0002-2767-3091 


\begin{abstract}
The objective of this work is to reflect on current conditions of individual formation, considering the current capitalist social structure and neoliberal ideology. To achieve this objective, the text is divided into three parts; the first provides elements for thinking about neoliberalism as an ideology; the second deals with individual formation under this ideology, with respect to currently required productivism and entrepreneurship, personality characteristics, favorable or contrary to democracy and related to forms of school violence; and the last part discusses the relationship between neoliberalism and the formation of the individual. It is argued that the neoliberal ideology hides the inexistence of the market, helping to concentrate capital in an ever smaller number of groups, and lack of perception of this can lead to the defense of the welfare state, which allows better material conditions of life for the population, which while important has nevertheless been the target of criticism, especially by thinkers of the Critical Social Theory. In order to manage this system based on concentration of wealth, a fascist administration is necessary, even though it may have the appearance of democracy; if it is an objective phenomenon, it does not dispense with individuals who support it, who are formed by a superficial relationship with reality, which enables an expression of violence, which indicates regressed personality needs.
\end{abstract}

Keywords: Formation of the individual. Social criticism. Neoliberalism.

\title{
Introdução
}

Em seu texto "Educação após Auschwitz", da década de 1960, Adorno (1995) defende que nenhum princípio para a educação deveria ser mais importante do que evitar que Auschwitz voltasse a acontecer; argumentou que se os educadores não tivessem consciência disso, a repetição da catástrofe poderia se repetir, mesmo porque as condições objetivas não se alteraram e propósitos fascistas sobreviveram também nas democracias sociais. Como modificar as condições sociais àquela época, e parece que nos dias de hoje também, não era possível, deveríamos nos voltar para a formação do indivíduo, de sua consciência, e a educação deveria se tornar política e analisar as forças sociais existentes. Como atualmente as questões atinentes ao genocídio voltam a preocupar, mesmo considerando que esse conceito foi ampliado em relação ao referido por Adorno, cabe à educação, que envolve também a escolar, entender politicamente o que ocorre, notadamente sobre a formação da consciência que pode dar guarida a ímpetos individuais fascistas que auxiliam a sustentar a catástrofe, para tentar impedir ao menos suas manifestações. 
Nesse sentido, politicamente, caberia pensar o neoliberalismo, que, já há algum tempo, não somente ganha hegemonia, graças à defesa de suas proposições e práticas desenvolvidas, mas também por se tornar alvo principal, quando não único, de seus opositores. Certamente, como se trata de um fenômeno mundial fortalecido desde a década de 1970, devem ser feitas críticas contundentes e precisas, e isso tem ocorrido, indicando a existência de uma resistência fundamental aos avanços do capital e às propostas e práticas fomentadas por aquele ideário. Caberia, entretanto, refletir se essas críticas não se desprendem das anteriores feitas a esse regime social que transforma a todos em coisas a serem trocadas por um equivalente que elimina qualquer possibilidade de diferenciação, de formação individual e de suas criações, determinadas também pelo sistema social existente, uma vez que, conforme Adorno (2015), em cada momento, a sociedade leva à regressão individual que precisa para se reproduzir.

Assim, o objetivo deste trabalho é pensar a atual formação dos indivíduos, quer por suas características de personalidade ou por suas capacidades e competências exigidas socialmente e visadas pela educação escolar, e sua relação com características atribuídas ao neoliberalismo, no que podem configurá-lo como ideologia, para que a real concentração do capital não seja enfrentada. Para o cumprimento desse objetivo, a exposição será dividida em três partes; a primeira trará elementos para se pensar sobre o neoliberalismo como ideologia, e, assim, os limites das críticas feitas a ele, como se sua implantação fosse real; a segunda se voltará para a formação individual quer em suas características de personalidade, favoráveis ou contrárias à democracia e relacionadas com formas de violência escolar, quer como ser produtivista e empreendedor; e a última parte trará considerações sobre a relação entre essa ideologia e a formação do indivíduo.

\section{O neoliberalismo como ideologia}

Se não há novidade no que se concebe como neoliberalismo, caso ele consista em ser basicamente uma ideologia, visualizar um novo alvo, quando essencialmente inexiste, pode acarretar a defesa de formas anteriores já criticáveis, como o estado de bem-estar social e a social democracia. Em relação a esses últimos, o neoliberalismo pode aparentar uma regressão social maior, mas é a continuidade de um conflito, no qual polos antagônicos - como Estado e mercado - revezam-se como agentes tidos como principais. 
No texto de Adorno (2004c), "Capitalismo tardio ou sociedade industrial?", o entrelaçamento entre o novo e o antigo fica visível; o autor argumenta que o capitalismo, no século XX, mantém as relações de produção tais como no século $\mathrm{XIX}$, ao mesmo tempo que ganha feição industrial, própria ao desenvolvimento das forças produtivas. Contrariando o prognóstico de Marx, essas últimas em vez de "explodir" as relações de produção são aprisionadas por elas.

Nos últimos tempos, a ideologia neoliberal, fortalecida a partir da década de 1970, tem sido criticada, considerando o enfraquecimento da atuação do Estado, que tenta minimizar as injustiças sociais provocadas pelo sistema capitalista (BRESSER-PEREIRA, 2009). O estado do bem-estar social, surgido como resposta à ameaça socialista na primeira metade do século passado, deveria garantir uma vida digna para seus cidadãos, com saúde, educação, segurança. Esse estado mudou inclusive a situação de pauperização do proletariado:

Os proletários têm mais a perder do que suas correntes. Seu padrão de vida não piorou, mas melhorou em comparação com as circunstâncias inglesas de cem anos atrás, conforme se apresentaram aos autores do Manifesto. Menor jornada de trabalho, melhor alimentação, moradia e vestuário, proteção aos familiares e à própria velhice, com o desenvolvimento das forças produtivas técnicas, os trabalhadores têm tido uma expectativa média de vida elevada (ADORNO, 2004d, p. 357, tradução nossa).

Em relação ao texto citado anteriormente de Adorno (2004c), também é interessante notar que o autor não utiliza nem o conceito de "Estado capitalista", nem o de "Behemoth", desenvolvidos por seus colegas do Instituto de Pesquisa Social, mas "capitalismo tardio", o que permite entender que é um sistema social e econômico anacrônico, e como explicitamente defendido por ele, ao contrário das previsões, revivido até não se sabe quando.

Para Harvey (2008), o neoliberalismo é mais um projeto que conseguiu o reestabelecimento das condições propícias ao acúmulo do capital do que a reorganização do capitalismo internacional. Quando há conflito entre os princípios neoliberais e a necessidade de reestabelecer o poder da elite, essa última prevalece, e aqueles princípios são abandonados ou distorcidos. Entre esses princípios, segundo esse autor, há o de mercado, que, tal como Korsch enunciou em 1941, deixou de existir: 
Sair do terreno em que a luta de classes dos trabalhadores contra o capitalismo foi travada na época anterior para o terreno em que deve ser continuado hoje pressupõe uma visão completa de um fato histórico que não é menos um fato, porque serviu como uma teoria base para as reivindicações do fascismo. Esse fato histórico que finalmente chegou hoje pode ser descrito como uma primeira abordagem, negativa ou positiva, em qualquer um dos seguintes termos: Fim do mercado, Fim do capitalismo competitivo, "Fim do homem econômico"; Triunfo da burocracia, de regra administrativa, do capitalismo monopolista; era dos planos russos de quatro anos, batalhas italianas no trigo, "Wehrwirtschaft" alemão; Triunfo do Capitalismo de Estado sobre Propriedade Privada e Empresa Individual (KORSCH, 2020).

Se não há mais mercado, esse se transforma em ilusão que oculta o poder econômico concentrado. Não há, portanto, que se criticar algo no neoliberalismo que não mais existe - o mercado -, mas a ideologia a que se refere. Se o mercado nunca foi livre, com os monopólios, os preços são diretamente administrados por quem os vende e não pela livre concorrência. O mercado ainda referido passa a ser o financeiro e o de trabalho: o dinheiro e o trabalhador são ainda as mercadorias a circular, mas para esse último, o emprego formal é cada vez mais raro, devido à crescente e desejável automação.

A ideologia da integração, como a nomeia Adorno (2004a), também tenta elidir a existência da luta de classes; e o estado do bem-estar social, em seu tempo, deveria diminuir as injustiças sociais, até chegar ao ponto de, em nome da burguesia, cuidar dos interesses dos trabalhadores:

A previsão de Marx foi inesperadamente verificada: a classe dominante se percebe tão radicalmente nutrida pelo trabalho alheio, que toma como assunto próprio seu destino, ter de alimentar os trabalhadores, e garante a 'existência do escravo no seio de sua escravidão' para consolidar a sua própria (ADORNO, 2004d, p. 359, tradução nossa).

Se a classe trabalhadora não tem consciência de classe (ADORNO, 2004a; LUKÁCS, 2018), continua a ocupar um lugar social propício à superação da escassez da produção material, e como essa atingiu um nível que permitiria eliminar toda miséria existente, para que o sacrifício do trabalho ainda seja exigido, é necessário criar, conforme Marcuse (1981), profissões sem ocupação, para que a exploração do trabalho pelo capital possa prosseguir. Se o capitalismo 
é um sistema anacrônico, todas as novas formas que assume, entre elas a neoliberal, são reproduções de algo que desesperadamente intenta sobreviver ao que lhe é contraditório: a possibilidade de sua superação.

O capital, no entanto, continua a se reproduzir por meio da mais-valia, e a fórmula para essa continua a ser "dinheiro-mercadoria-dinheiro", o que a torna irredutível ao capital financeiro; mesmo as crises financeiras, desse modo, devem ser entendidas como crises do capital, e não por serem especulativas; se as especulações financeiras geram ilusões sobre a produção material, é o enfraquecimento desta, por não ser tão rentável e mais suscetível a riscos, que leva o capital a especular. Mais do que isso, o neoliberalismo, por ser a ocultação dos poucos grupos que concentram o poder, deve garantir a ausência de riscos, o que é possível, paradoxalmente, com a eliminação do mercado e, assim, da concorrência. Nessa direção, Harvey (2008) argumenta que o mercado, descrito ideologicamente como forma de promover a competição e a inovação, tornouse veículo da consolidação do poder monopolista. E os grupos que concentram renda influem diretamente nas decisões políticas a seu favor.

Os pensadores da Escola de Frankfurt criticaram o estado de bem-estar social existente nos países do nomeado primeiro mundo, que possibilitou, como ressaltado, nesses países, uma vida com algum conforto a todos os cidadãos, ainda que a distinção entre as classes sociais prosseguisse (ADORNO, 2004a; MARCUSE, 1982). O descontentamento com uma sociedade de malhas estreitas foi expressado pelos diversos movimentos sociais da década de 1960, indicando que a ampliação da distribuição dos bens materiais para todos, naqueles países, não trouxe, necessariamente, bem-estar. Tratava-se de uma sociedade que deveria administrar o interesse de poucos, com meios eficazes, em detrimento da maioria da população, o que já estava presente no período da Segunda Guerra Mundial. Em 1947, Horkheimer e Adorno (1985) escreveram:

Nas condições atuais, os próprios bens da fortuna convertem-se em elementos do infortúnio. Enquanto no período passado a massa desses bens, na falta de um sujeito social, resultava na chamada superprodução, em meio às crises da economia interna, hoje ela produz, com a entronização dos grupos que detêm o poder no lugar desse sujeito social, a ameaça internacional do fascismo: o progresso converte-se em regressão. (HORKHEIMER; ADORNO, 1985, p. 15). 
A condução fascista do capital concentrado, ao que parece, prosseguiu sob a égide do neoliberalismo. Na prática, segundo Anderson (1995) e Harvey (2008), os governos neoliberais aumentaram as taxas de juros, diminuíram os impostos dos rendimentos altos, retiraram os controles dos fluxos financeiros, aumentaram o nível do desemprego, combateram os sindicatos, cortaram gastos sociais e iniciaram a privatização dos programas e empresas estatais.

Os sindicatos, tal como Horkheimer e Adorno (1985), já na década de 1940, e Marcuse (1982), duas décadas depois, assinalaram, passaram a se tornar sindicatos de resultados, quando não propícios a líderes que não deixavam de ameaçar também os trabalhadores que lhes resistissem. Esse pragmatismo foi ressaltado também por Harvey (2008), mas devido ao aumento do desemprego, que tornou os sindicatos mais moderados em suas reivindicações. Ora, aqui se tem três diferentes motivos para a mudança nos objetivos dos sindicatos dos trabalhadores. Para Horkheimer e Adorno (1985), trata-se de uma elite de trabalhadores que administram seu poder sobre os demais trabalhadores; para Marcuse (1982), ocorreu a separação entre a luta pela revolução socialista e a luta por melhores condições de trabalho, e essa última não deixa de repor o poder do capital; e para Harvey (2008), trata-se de salvar o que for possível, considerando o exército industrial de reserva, cada vez mais amplo; mas em nenhuma dessas perspectivas apresenta-se a liberdade individual de pelo seu mérito conseguir a ascensão social, algo presente nos discursos neoliberais sobre o mérito do trabalhador.

$\mathrm{O}$ anacronismo do Capital o faz girar em falso, impedindo, como mencionado antes, uma liberdade já possível, tendo em conta o avanço das forças produtivas; e quanto mais isso é verdadeiro, mais a ideologia deve agir para ocultar a cada vez maior contradição entre a realidade opressiva existente e a possibilidade de libertação. E como Horkheimer e Adorno (1973) mostraram, a ideologia, que também é histórica, alterou-se dos tempos de Marx para o presente, e não é mais pelo contraste entre discurso e realidade que é denunciada; para o convencimento das pessoas é necessário atuar, conforme Marcuse (1981), com a engenharia de comportamento; para Horkheimer e Adorno (1973), os mecanismos psíquicos devem ser acionados para se negar o constatável: a exploração existente. Antes da compreensão, já os sentidos são afetados, o que é referendado na exposição que esses autores fazem da indústria cultural, que se coloca no lugar dos a priori kantianos.

E o neoliberalismo é também, e, sobretudo, ideologia, e tal como enunciado no parágrafo acima deve afetar o pensamento e os sentidos. Não se trata somente de ocultar a realidade, mas de eliminar a possibilidade de conceber outras formas sociais de existência. Segundo Bresser-Pereira (2009), já na década de 1960, a separação entre economia e política proposta por economistas americanos 
reduziu a economia à matemática, tentando torná-la independente da política. Essa redução, presente também no neoliberalismo, é enfatizada por Bordieu (1998), que a chama de "ficção matemática", ao abstrair as reais condições sociais que a tornam possível. Horkheimer e Adorno (1985), ao final da Segunda Guerra, já indicavam que o pensamento passa a coincidir com a matemática, o que converte o movimento do esclarecimento no mito que objetivava superar.

Paulani (1999) destaca que o neoliberalismo não é ideologia como falsa consciência, própria à doutrina liberal, mas um sermão, um dogma, que não admite contestação. Marcuse (1982) irá nomear de ideologia da sociedade industrial ou pensamento unidimensional e Habermas (1983) de ideologia da racionalidade tecnológica a afirmação da realidade tal como percebida como sendo a única existente; ressaltam que o pensamento não consegue mais ir além do visível, do existente, e perceber a "negação determinada", tal como discutida por Horkheimer e Adorno (1973). Dessa forma, a crítica é reduzida ao aperfeiçoamento do que há e não à possibilidade de já haver produção material suficiente para que a sociedade se constitua de outro modo, que não por meio da exploração do trabalho alienado, e realizar a liberdade e a igualdade entre os indivíduos.

Se os pensadores frankfurtianos puderam delimitar, já na década de 1940, antes do fortalecimento do neoliberalismo, a concentração do capital, a mudança dos objetivos dos sindicatos e a nova constituição da ideologia, pode-se dizer dessa proposta ideológica que defende um mercado inexistente, que seus componentes, e, assim, ela própria, não são novos.

Segundo Paulani (1999), o objetivo do neoliberalismo era liberar o capitalismo de regras, enfrentando a intervenção do Estado no mercado. Para seus propositores, a igualdade promovida pelo estado de bem-estar social era contrária à liberdade individual e, consequentemente, contrária à prosperidade social; a noção de individualismo defendida é diferente da que servia como base para o conceito de indivíduo no liberalismo; a doutrina voltada para a política, com lastro filosófico, passa a se tornar um ideário que defende uma política econômica dirigida à desregulamentação do mercado em pleno capitalismo dos monopólios.

Bresser-Pereira (2009) é incisivo ao defender que o neoliberalismo é ideologia produzida pelos ricos contra os pobres, contra a social-democracia. Harvey (2008) também acentua que o neoliberalismo foi um projeto para devolver o poder à classe dominante. Assim, mais uma vez, não há nada de novo no neoliberalismo que já não se apresentasse anteriormente. Mas mesmo a devolução do poder ao capital é algo a ser pensado, pois, o estado do bem-estar social, anterior ao neoliberalismo, não deixou de favorecer o capital. 
Harvey (2008) indica o fortalecimento da social-democracia em vários países, após a Segunda Guerra Mundial, quando o Estado deveria ampliar sua interferência na economia para resolver problemas como o desemprego, promover o desenvolvimento econômico, e, também, o bem-estar dos cidadãos. O emprego de políticas fiscais e monetárias "keynesianas" permitiu reduzir o sofrimento dos mais pobres; conforme o autor, foi estabelecido um "compromisso de classe" entre capital e trabalho. A classe trabalhadora se fez representar, por meio de partidos e sindicatos, influindo na intervenção do Estado. Mas, o conflito permaneceu entre aqueles que advogavam a intervenção do Estado e os principais beneficiários do capitalismo monopolista.

Para Anderson (1995), Bresser-Pereira (2009) e Paulani (1999), o neoliberalismo tem origem após a Segunda Guerra Mundial, sobretudo na década de 1950; o texto "O caminho da servidão", de Friedrich Hayek, de 1944, foi sua base teórica. Segundo Anderson (1995), a igualdade promovida pelo Estado, para Hayek, prejudicava a possibilidade de concorrência, vital para o progresso de todos. Antes do período do neoliberalismo, no entanto, a Guerra Fria já expressava que o capital continuava como uma das forças sociais existentes, e essa nova ideologia pode servir para fortalecê-lo e não para criar novas alternativas sociais.

Se o neoliberalismo defende a liberdade individual, a ser encontrada em um ilusório mercado, não defende necessariamente a democracia. Segundo Anderson (1995), a Inglaterra foi o primeiro país desenvolvido a adotar a perspectiva liberal, seguido pelos Estados Unidos da América. No início da década de 1980, vários países - Alemanha, Dinamarca e outros países do norte da Europa - também adotaram uma guinada ao espectro político considerado de direita. Os EUA, conforme Anderson (1995), que nunca chegaram a estabelecer um Estado de Bem-Estar Social, tiveram uma variação distinta do neoliberalismo, que trazia como prioridade a competição com a União Soviética, indicando, como na Guerra Fria, o prosseguimento da disputa entre sistemas sociais.

Essa oposição entre as duas principais potências mundiais também se refletiu, conforme Harvey (2008) e Anderson (1995), em vários países que, após os anos dourados do capitalismo, derrubaram ditaduras e elegeram governos considerados de esquerda: França, Espanha, Itália, Portugal, Grécia, Polônia e Hungria. Foram alternativas ao neoliberalismo e tinham como base movimentos de trabalhadores e populares. No entanto, em um mundo em que os interesses do capital são preponderantes, os governos de esquerda que chegarem ao poder terão seus limites e serão obrigados a seguir a ortodoxia neoliberal, como ocorrera, o que indica que a crítica não deve ser feita ao neoliberalismo, mas à mentalidade do lucro, quer provido pelo Estado, quer pelas empresas privadas, sendo que o fortalecimento da elite econômica é a regra (HARVEY, 2008) - 
esse autor mostra também outra tendência que fortaleceu o capital a partir do final da década de 1970: a liberalização da economia chinesa, dirigida por um governo comunista, tornando a China um país com altas taxas de crescimento.

Com isso, no século XX, dois modelos de sociedade se opuseram. No início, com a Revolução Soviética e a crise da bolsa de Nova Iorque, a versão progressista, com a intervenção do Estado na economia passou a predominar; a partir dos anos de 1970, inverte-se o campo de forças. Independentemente do regime político, a concentração de renda aumentou, diminuindo os salários e dando mais lucro ao capital. Para confirmar isso, Harvey (2008) mostra que, além dos efeitos ideológicos, o neoliberalismo, após sua implantação ao final dos anos de 1970, concentrou a renda nos Estados Unidos da América, na Inglaterra e em diversos outros países e aumentou substancialmente os salários dos diretores de empresas em comparação com os demais trabalhadores. Na Rússia, após a queda do Muro de Berlim, ganha força uma pequena e poderosa oligarquia; também na China, a desigualdade de renda aumentou; dessa forma, democracias e ditaduras puderam se valer do neoliberalismo para que, de modos distintos, continuasse a concentração de capital e a criação de novas elites econômicas, e, portanto, políticas.

Apesar da ênfase em um mercado inexistente no capitalismo dos monopólios, a ideologia neoliberal necessita, como ressaltado, de um Estado forte no que se refere às tarefas de fiscalização, cobrança e favorecimento dos oligopólios e monopólios, quer pelas leis sancionadas, quer pela infraestrutura custeada pelos impostos, e a primeira experiência ocorreu, conforme Harvey (2008), na ditadura do general Pinochet no Chile. Assim, quer o inexistente mercado, quer o falso estado neutro visam a administração de mercadorias e pessoas, também, e cada vez mais, convertidas em mercadorias, em favor dos poucos grupos dominantes, que não dispensam o uso do aparato legal para resguardar seus interesses. Deste modo, o neoliberalismo não deve ser considerado uma novidade, mas uma nova forma de ocultar a sociedade administrada, e como forma de ocultação é ideologia, que defende o inexistente: um mercado livre e/ ou um estado neutro a favor da regulamentação desse falso mercado.

A passagem do capitalismo concorrencial para o de monopólios é assinalada por Horkheimer e Adorno (1985); com essa passagem, há a necessidade de uma administração mais centralizadora, fascista, conforme pode ser percebido pelo trecho de autoria deles exposto páginas atrás; não se trata mais da produção de mercadorias em uma sociedade sem um sujeito coletivo, que representasse a humanidade, mas de uma sociedade na qual aquela produção é possuída por grupos que exercem o poder no lugar daquela humanidade. Tudo se torna alvo de uma administração aparentemente neutra, que reduz tudo à ordem do que é administrável: também a cultura, também as pessoas. 
Uma cultura reduzida a bens materiais administrados, no entanto, conforme Adorno (2004b), é algo que perdeu a possibilidade de crítica, possibilidade esta que exige um afastamento para melhor refletir o que se afasta, corroborando a ideologia da racionalidade tecnológica mencionada anteriormente. Tal administração pode ser feita pelo Estado ou pela iniciativa privada, mas tem a mesma feição: oculta os beneficiários maiores dessa administração. Não casualmente, mesmo na área de relações pessoais, utiliza-se o termo "gestão de pessoas", com o qual se manifesta claramente a manipulação de "coisas", e, assim, a produção de reificação. E claro, o conflito social entre classes também é administrado, isto é, negado por aqueles que enaltecem a meritocracia.

Como indicado antes, as contradições sociais não desaparecem com a mudança do capitalismo, mas assumem outra feição. Uma mudança essencial ocorre naqueles que dominam: são também dominados pelo sistema que os beneficia; nas palavras de Adorno (2004c, p. 335, tradução nossa): "O domínio sobre os seres humanos continua sendo exercido por meio do processo econômico. Objetos que não são apenas as massas, mas também aqueles que comandam e seus apoiadores". Tal como Marx (1984) pode enunciar, não se trata de analisar e criticar os capitalistas, ainda que esses não sejam dignos de maiores elogios, mas de pensar a relação entre capital e trabalho. No estudo de Wright Mills (1951), evidencia-se como os proprietários de empresas menores tornam-se empregados das empresas maiores que integram aquelas em seu patrimônio: diminui-se o número de capitalistas, que se fortalecem, porque mais concentrado é o capital.

Horkheimer, Adorno e Marcuse, em seus trabalhos, apresentaram críticas a sistemas sociais totalitários: o nazifascismo, o stalinismo e a democracia formal, mas não real, presentes, sobretudo, em países desenvolvidos. A questão da dominação é central em seus trabalhos e não se restringe à exploração presente no capitalismo. Ao defenderem que Odisseu foi o protótipo do indivíduo burguês e que a sociedade da época da Ilíada e da Odisseia apresentou-se com traços do que muito tempo depois seria considerada uma sociedade mercantil, marcam uma perspectiva histórica que descreve a dominação sob diversas formas, e também a possibilidade de sua superação. Ao compreenderem a nossa história como a da burguesia, indicam que a contradição entre seus momentos conservadores e progressistas deve ser buscada em sua imanência. Não importa de onde venha a dominação: do mercado, do Estado, de grupos fascistas que administram o poder, mas, sim, a sua denúncia e a superação das condições objetivas que a expressam.

A dominação da natureza, que envolveu também a dominação da natureza humana, caracterizou e ainda caracteriza nossa história, mas sua necessidade objetiva já não mais se justifica, se algum dia se justificou. $\mathrm{O}$ avanço das forças produtivas, como mencionado antes, atingiu condições propícias à eliminação da miséria; se isso não ocorre, é por motivos políticos e não mais, 
preponderantemente, econômicos. Assim, a crítica deles não deve ser dirigida somente às formas de dominação presentes, tal como o nomeado neoliberalismo, mas à perpetuação da dominação, independentemente de sua forma. Para Adorno (2004e), as fontes do fascismo, utilizado para a administração capitalista, transcendem a economia, e por isso, sua crítica, como ressaltado, se expande para toda forma de dominação:

A tendência - falo expressamente de tendência - segundo a qual a sociedade atual, se suas formas políticas deveriam aderir radicalmente e por força às econômicas, é dirigida imediatamente, em sentido pregnante, de forma metaeconômica, isto é, não mais por formas definidas pelo mecanismo de troca clássico. Não deveria haver controvérsia alguma entre nós quanto à existência de tais tendências. Então, o conceito de domínio volta a atingir, mais uma vez, certa preponderância frente os processos puramente econômicos. Do ponto de vista estrutural, as formas parecem ter sido produzidas ou delineadas, por meio de um movimento socioeconômico imanente, formas que extrapolam o contexto de determinação da pura economia e da dialética imanente da sociedade, tornando-se independentes até certo ponto, e de modo algum para o bem (ADORNO, 2004e, p. 54, tradução nossa).

Ao final da nomeada Era de Ouro do capitalismo, em 1969, Horkheimer e Adorno (1985) reeditam sua obra "Dialética do esclarecimento". Ainda que tenha sido uma década de transformações culturais importantes, como os movimentos de contracultura, os movimentos estudantis, os movimentos revolucionários, seus autores afirmam: "[...] o desenvolvimento que diagnosticamos neste livro em direção à integração total está suspenso, mas não interrompido; ele ameaça se completar através de ditaduras e guerras" (HORKHEIMER; ADORNO, 1985, p. 10). De fato, no Brasil, por exemplo, em 1969, a ditadura inaugurada em 1964 amplia seus poderes. Mas o combate a essa e outras ditaduras também se apresentou, nessa década, naqueles movimentos. Ditaduras, guerras e movimentos contrários a elas mostram as contradições sociais, que tendem a ser suspensas mas não eliminadas pela administração como um fim em si mesmo, que aparentemente neutro, serve aos poderes dominantes. A cisão entre indivíduo e sociedade se ampliou e os indivíduos são mais diretamente manipulados por essa última, sobretudo pela alienação, resultante dessa cisão. 


\section{A formação do indivíduo alienado}

A formação para uma sociedade que administra e assegura os bens dos mais poderosos deve também ser administrada por esses interesses. Para a manutenção de uma direção fascista, são necessários tipos de personalidade autoritária que ocupem cargos de direção, na política e nas empresas públicas ou privadas, e os que os apoiem. São necessários executivos que utilizem a racionalidade técnica para seu bom desempenho, independentemente dos fins empresariais: a mesma racionalidade é utilizada para a fabricação de armas e de remédios; racionalidade propensa à maior produtividade; e a cultura e, dentre as suas instituições, a escola deve preparar esses executores de metas, assim como os que devem seguir a hierarquia e a obediência para manter os empregos, cada vez mais raros, segundo Marcuse (1982), em função da automação crescente e pela obsolescência industrial planejada para não diminuir o lucro.

Como se trata de um desemprego estrutural, conforme Marcuse (1981), tendo em vista que, ao contrário da época analisada por Marx (1984), em relação ao avanço da maquinaria, não foram e não serão criados novos empregos para substituir os anteriores, a não ser o de produção de mercadorias para satisfazer falsas necessidades, não por acaso, depois do crescimento das franquias, uma forma de pagar para trabalhar sob as recomendações obrigatórias do dono, surge o incentivo ao empreendedorismo. A escola, com seu objetivo de preparar para o mercado de trabalho, deve se preocupar em desenvolver, em seus alunos, habilidades técnicas e competências para trabalhar em equipes hierárquicas ou sozinhos conseguirem inventar algo para vender.

Silva (2018), ao analisar a recente Base Nacional Comum Curricular (BNCC) para o Ensino Médio, destaca o caráter adaptativo; essa "formação administrada", conforme expressão que utiliza, é contrária a uma formação que contemple uma dimensão histórico-cultural, propícia à diferenciação individual e à autonomia, e pouco propensa à reflexão. Essa nova legislação, que segundo a autora não é nova, já tinha sua disposição enunciada na legislação educacional da década de 1990. Esse caráter adaptativo pode ser visualizado pela restrição das disciplinas obrigatórias à Matemática e ao Português e pela retirada da obrigatoriedade das disciplinas de Filosofia e Sociologia. Ainda conforme essa autora, as competências exigidas na formação são propícias àquela adaptação e não à crítica.

A modificação proposta na $\mathrm{BNCC}$ considera a adequação às supostas mudanças no mercado de trabalho, que, como argumentamos, é cada vez mais restrito, devido ao desemprego estrutural, acarretado pela crescente automação. 
Favero, Consalter e Tonieto (2020) também ressaltam esse caráter instrumental da atual proposta para o Ensino Médio, que tem como base a "Pedagogia das competências", própria à aprendizagem utilitária.

As críticas feitas por Silva (2018) remetem à pseudoformação descrita por Adorno (2004a), na década de 1950: uma tendência a uma relação externa com os conteúdos ensinados e próprios a servirem para a adaptação do indivíduo a uma sociedade que exclui a todos, e essa pseudoformação ocorre de dois modos: adaptativa (pragmática) e pela valorização da cultura como fim em si mesmo. A primeira, ao que tudo indica, ganhou primazia, e a última não deveria ser somente vinculada à erudição superficial, mas também à crítica à sociedade. Adorno (2004a) defende uma relação entre a sociedade e a cultura - em que a formação ocorra pela incorporação dessa cultura -, na qual haja um movimento inicial de distanciamento, para que haja reflexão sobre a sociedade e um retorno a essa, para que possa ser criticada e, se e quando possível, modificada. Assim, o mero ensino da Filosofia e da Sociologia não basta, por si só, para a crítica da pseudoformação e, consequentemente, para a sociedade que objetivamente a proporciona.

Favero, Consalter e Tonieto (2020) indicam o caráter controlador da educação por uma avaliação padronizada pelo Estado em função das necessidades do mercado e, assim como Taffarel e Beltrão (2019), associam essas mudanças com o neoliberalismo presente na educação. Taffarel e Beltrão (2019) indicam que a BNCC para o Ensino Médio é uma forma de empobrecer ainda mais a formação dos estudantes provindos da classe trabalhadora. Mas, cabe ressaltar que esses autores não têm compreensão similar à defendida neste texto de que não se trata de uma nova forma de capitalismo - neoliberalismo -, mas da concentração de renda contínua. Favero, Consalter e Tonieto (2020) chegam a apresentar a centralização da educação privada em poderosos grupos que cada vez são em menor número, caracterizando desta forma o capitalismo de monopólios, e, ainda assim, mantêm a crítica à ideologia que nega a existência desses monopólios.

O desenvolvimento de conhecimentos e habilidades contribui para manter o progresso dentro da ordem, no trabalho e fora dele. Mas, como a sociedade é contraditória, a educação escolar comporta também a crítica a esse tipo de formação. Como Adorno et al. (1950) defendem, na autorreflexão e na reflexão sobre o mundo, que, apesar de sua distinção, são correlatas, não cabe separar, na formação possibilitada pela escola, as características pessoais, comportamentos e habilidades desenvolvidos dos conhecimentos adquiridos, que são fundamentais para superar a alienação.

Se, como defendido no início deste texto, a educação deve ser política, dirigida à formação da consciência, a consciência alienada dos conflitos sociais e a consciência reificada, que converte todos em objetos de administração (manipulação), devem ser criticadas, e, como desenvolvido na parte anterior, 
a ideologia, quer ao ocupar a consciência por uma visão reduzida do mundo ao existente ou por ser mentira manifesta, deve ser combatida, na direção de retirar a base subjetiva do apoio ao extermínio objetivo. Deve-se enfatizar que a violência e a tendência à não violência, presentes e fomentadas na escola, são mediadas socialmente (ADORNO, 2004a).

No tocante à violência social e à formação da personalidade, Horkheimer e Adorno (1985) argumentaram que no período nazista não era mais o antissemitismo que existia, mas a mentalidade do ticket; a adesão a um conjunto de adjetivos - conservadores ou progressistas - que reduzia os seres a essas qualidades e à fixidez da relação entre esses adjetivos; um pensamento estereotipado. No estudo sobre personalidade autoritária, Adorno (2019) indica alguns tipos, além do característico sadomasoquista - entre eles, destacam-se o psicopata, cujo desejo de destruição é visível, e o manipulador, cujo prazer se encontra em "fazer coisas", na eficiência -; a alienação social e a transformação da vida e das pessoas em coisas a serem manipuladas são claramente perceptíveis. Tal como Adorno (2004a) indica, há elementos psíquicos importantes que constituem a pseudoformação, entre eles o narcisismo e a paranoia, correlatos de uma educação para a alienação, para a indiferença. Não há experiência propriamente dita, mas contato superficial com conteúdo que não guarda sentido para aqueles que estudam, o que leva o frankfurtiano a afirmar que o aprendido logo deve ser "apagado" para que novos conteúdos possam, superficial e brevemente, ocupar o pensamento que não se volta à compreensão do objeto, mas à repetição de sua aparência.

Naquele momento, na década de 1940, no domínio dos monopólios, um indivíduo mais regredido psiquicamente do que o clássico autoritário se fazia presente (CROCHICK, 2019); nesse tipo, a constituição de um objeto da paixão - de ódio - não mais precisava se configurar, o que importava era o movimento do impulso destrutivo, não importa contra quem. Assim, o judeu, à época do nazismo, era um alvo assinalado pelo Estado alemão a ser perseguido, mas não era amado, nem odiado, apenas um objeto permitido para que a fúria da sensação da real impotência pudesse ser descarregada.

Em texto publicado em meados da década de 1950, portanto nos anos dourados do capital, Adorno (2015) argumenta que os indivíduos neuróticos estudados por Freud são substituídos pelos narcisistas, que abdicam da consciência e agem somente em função de seus interesses, podendo ser socialmente agradáveis. O narcisismo, no entanto, é um movimento da pulsão que deve retornar ao ego, em ocasiões de sofrimento, e retorna ao narcisismo coletivo - o amor pela pátria ou outro ideal -, quando o narcisismo individual é criticado. Em suma, se no liberalismo parcela da população tinha de desenvolver um ego em sua relação com o mundo objetivo, para que este continuasse a ser 
produzido, na sociedade administrada, os indivíduos devem se voltar para si mesmos, e não mais para a produção, mas para o consumo de bens supérfluos, já que a permanência de um ego frágil é nutrida por esse consumo.

Se o narcisismo já fora indicado como a regressão psíquica presente nos anos dourados do capitalismo, somente a partir do final da década de 1970 começam a surgir obras destacadas sobre o narcisismo. Em 1979, Lasch publica "A cultura do narcisismo" (LASCH, 1983); em 1982, Green publica "Narcisismo de vida, narcisismo de morte" (GREEN, 1988). Coincidentemente, sem que se trate de uma relação entre causa e efeito, o neoliberalismo e a discussão sobre o narcisismo se fortalecem a partir dessa década.

Na década de 1980, surge outro fenômeno, conforme Crochick (2019), correlato a personalidades psiquicamente mais regredidas: o bullying, direcionado a satisfazer desejos primitivos de onipotência, como o da dominação plena e destruição de quem não reage suficientemente à violência; não tem um objeto delimitado, como é o caso do preconceito. Alguns pesquisadores (ANTUNES; ZUIN, 2008) têm defendido que a discussão do bullying empobrece a que foi feita pelos frankfurtianos acerca do preconceito; dados de pesquisa recente (CROCHICK, J.; CROCHICK, N., 2017), no entanto, indicam que ambos os fenômenos se relacionam, mas não se confundem, e que se o preconceito pode trazer uma defesa da ordem moral e social existente e um desejo latente de destruí-la, o bullying só contém esse último, e pode ser qualquer um o alvo a ser destruído; o preconceito indicaria uma personalidade menos regredida, pois necessita de um objeto delimitado (judeu, negro, pessoa com deficiência) para projetar seus desejos proibidos e suas angústias; de outro lado, para o autor do bullying, qualquer objeto que não resista serve para seu desejo de dominação e de violência, o que leva a pensar que o bullying é uma forma mais primitiva de violência do que o preconceito (CROCHICK, 2019).

Tal como defendido por Adorno (2015), quanto mais a sociedade se aperfeiçoa do ponto de vista técnico e administrativo, menos os indivíduos são necessários, e o indivíduo formado com um ego mais frágil - comum aos narcisistas, psicopatas e manipuladores - ilustra essa transformação: tendencialmente a sociedade gera indivíduos mais regredidos, quer para as relações sociais ou para a compreensão do mundo. Uma cultura que não proporciona uma experiência, um contato substancial com o mundo, é a que possibilita a insensibilidade, a indiferença para com os objetos com os quais o indivíduo regredido se relaciona de acordo com seus desejos e temores imaginários; neste sentido, uma educação que possibilite a abertura para a experiência com os objetos seria contrária à violência, mas, para isso, a formação não deveria ser externa, alheia aos estudantes, e, sim, calcada na compreensão 
das contradições sociais que devem ser superadas, contradições essas que podem ser percebidas em cada objeto a ser transmitido e em cada habilidade a ser desenvolvida em sua relação histórica com a sociedade.

Se o narcisismo é mais atual do que o sadomasoquismo em função das condições sociais existentes, essas correspondem, conforme desenvolvido antes, à maior concentração do capital, e é à sua ideologia que os desejos individuais são associados. Tal como analisa Freud (2011), o conteúdo ideacional tem como base necessidades psíquicas fortes, e Adorno et al. (1950) apresentam como hipótese de seu estudo sobre a personalidade autoritária que um conjunto de ideias tem adesão dos indivíduos mediante seus desejos expressados por sua estrutura de personalidade. A cultura medeia a relação entre os indivíduos e a sociedade, serve como um filtro para que essa possa ser percebida e interpretada; como, conforme mencionado antes, provém de uma sociedade contraditória, a cultura não contém somente uma percepção deturpada do mundo que caracteriza a ideologia, mas também a possibilidade de sua crítica; desta forma, quanto mais diversificada e rica for uma cultura, mais os indivíduos conseguem se diferençar e expressar seus desejos; quanto menos diversificada e mais pobre for uma cultura, menos os indivíduos conseguem expressar seus desejos.

A indústria cultural, no entanto, segundo Horkheimer e Adorno (1985), traz o fetichismo das mercadorias culturais, e, nesse sentido, transmite ideologia, no caso a fixidez da realidade existente. Promove a imitação da aparência como se essa última fosse o real, e assim obriga à adaptação ao existente; empobrece dessa forma a possibilidade da percepção de contradições sociais; essas, por vezes, são percebidas, e quando isso ocorre alguns indivíduos aderem à mentira manifesta para a satisfação de impulsos primitivos e nem sempre permitidos, como a crueldade e a imitação possibilitada quando o objeto de imitação é ridicularizado.

Se a indústria cultural se caracteriza pela repetição do sempre igual, não oferece objetos específicos aos quais as pulsões individuais possam se associar. Segundo Freud (1997), os objetos oferecidos pela cultura permitem a diferenciação individual, pelo contraste entre fantasia e realidade; se a cultura, como a transmitida pela indústria cultural, não provê objetos, produz uma pulsão que se satisfaz pela repetição, o que caracteriza a compulsão. Se como defendido antes, o bullying pode prescindir de objetos para seu impulso destrutivo, a indústria cultural auxilia em seu desenvolvimento, obstruindo, por sua vez, a possibilidade de o indivíduo se diferençar pela experiência com os objetos oferecidos pela cultura.

Para que o desenvolvimento individual seja possível, é fundamental, conforme Adorno (2004a), uma relação substancial do aluno com os conteúdos oferecidos, que não podem ser menos substanciais para a adaptação à sociedade existente e para a superação de seus limites. Os dois modos de pseudoformação 
enunciados antes - a cultura aprendida como meio somente de adaptação ou a exaltação da cultura como cultura - são fomentados pela indústria cultural e fortalecidos pela escola; quando essa não a critica e reproduz a ausência de conteúdo substancial transmitido por aquela, torna-se parte dela.

Se a educação escolar não deve se dirigir somente às questões da violência, que não se restringem à vida escolar, e se é reproduzida na vida de adultos na sociedade, também tem como objetivo fundamental a transmissão de conteúdos e o desenvolvimento de habilidades. Pensando nas tendências da educação brasileira nas últimas décadas, pode-se pensar na ênfase no método científico em detrimento do saber próprio às humanidades da década de 1970, na ênfase nas competências e nas habilidades, com os parâmetros curriculares da década de 1990, que se estendem na atual proposta da Base Nacional Comum Curricular, conforme citado antes, no incentivo à discussão de projetos pessoais, à proatividade e ao empreendedorismo. Tais propostas, conforme Taffarel e Beltrão (2019), contribuem para a conformação social à precarização do trabalho incluindo a aceitação de subempregos.

Ora, no capitalismo dos monopólios, com o emprego cada vez mais raro, é difícil pensar em alternativas para um projeto individual, e também para o empreendedorismo, que servem como indicação clara de que cada um tem de aprender a cuidar de si mesmo, sem depender das opções sociais, sendo essas, por sua vez, cada vez menos reais. Educa-se, assim, para o que fazer em uma sociedade de desemprego estrutural. Se os interesses objetivos do capital estão resguardados, os indivíduos podem conflitar entre si sem que aqueles interesses sejam ameaçados. Assim, mais do que nunca a educação é para a alienação, sobretudo alienação e desconhecimento da vida que já seria possível. Uma formação para a alienação que não precisa da incorporação da cultura, pois essa perde cada vez mais a possibilidade de reflexão por meio da experiência com objetos substanciais, como o são a liberdade, a igualdade, a justiça, a felicidade, a solidariedade e a autonomia; reflexão que não deveria se constituir externamente a esses objetos.

\section{Neoliberalismo e formação para a alienação}

Se na primeira parte deste trabalho foi destacado o caráter ideológico do neoliberalismo, que oculta o avanço da concentração do capital como continuidade do capitalismo dos monopólios, a crítica à formação do indivíduo para a alienação por Adorno (1995 e 2004a) ao final da década de 1950 e na 
década de 1960 também foi ressaltada. Aliás, o fracasso da educação já estava descrito nos "Elementos do antissemitismo" de Horkheimer e Adorno (1985). O desvio da atenção da desgraça das camadas mais pobres para o ódio ao judeu, o ressentimento que se voltava contra ele, já era, segundo esses autores, um objeto intercambiável.

$\mathrm{Na}$ época do nazismo, as características psíquicas mais primitivas dos indivíduos já eram visadas pelo poder, e isso prosseguiu após a derrota desse sistema. Não é o neoliberalismo que leva a essa regressão, mas a posse do capital, presente quer no Estado do Bem-Estar Social, quer na doutrina teológica do mercado, conforme se refere Hobsbawm (1995) ao neoliberalismo. Certamente, não é indiferente, sobretudo aos mais pobres, que o Estado ofereça compensações às injustiças sociais produzidas pelo mercado, mas como esse não existe mais, as benesses oferecidas por esse Estado, representante mais do capital do que da sociedade, impedem a superação dos conflitos, pois sequer são percebidos.

Nas décadas de 1970 e de 1980, houve: 1- o fortalecimento da doutrina do neoliberalismo, para ocultar a concentração do capital; 2- discussões sobre o narcisismo, uma formação psíquica mais regredida de personalidade em relação ao sadomasoquista de outrora; e 3- discussões sobre o bullying, uma forma de violência mais primitiva do que o preconceito, sobretudo na vida escolar, e seus impactos sobre a vida psíquica, escolar e adulta. E esses fenômenos ocorrem em uma sociedade cada vez mais aperfeiçoada do ponto de vista técnico e administrativo, que permite esquecer os conflitos sociais, resguardando os interesses dos que pertencem à elite social, e a formação dos indivíduos pode se tornar cada vez mais regredida; a relação com a cultura e com a sociedade é externa, alheia aos interesses mais prementes do próprio indivíduo: sua autoconservação, e mais do que isso, a possibilidade de sua autodeterminação. A identificação entre os indivíduos deve ser negada, em nome da autoconservação, e a educação, também a escolar, favorece o desenvolvimento da frieza, da insensibilidade, a incapacidade de diferençar entre si mesmo e os outros e entre os outros; mas a sensibilidade, a capacidade de diferençar expressa a inteligência humana, e quando essa é reduzida à repetição do existente, regride.

O neoliberalismo e a concomitante regressão psíquica, que se dirige para formas mais primitivas de destruição, expressam a continuidade da dominação de poucos sobre muitos, e todos têm dificuldades de admitir a impotência que têm frente ao que percebem: a vida falsa existente e a possibilidade de sua superação. Formar uma consciência que permita perceber a falsidade das propostas do neoliberalismo e das consequentes exigências individuais é fundamental, e os educadores não deveriam abandonar esse objetivo, quer pela transmissão da cultura, como propriedade histórica de todos, cuja aquisição permite a individuação, quer pela possibilidade de os alunos poderem se expressar pelas 
linguagens aprendidas. Essa individuação e possibilidade de expressão dos desejos e medos podem evitar as violências irracionais de modo que possamos identificar, com precisão, os alvos contra os quais devemos lutar, para que as ameaças à vida, geradas pela sociedade, sejam extintas, visto que as condições objetivas do fascismo ainda se mantêm, promovendo novas Auschwitz, indicando que a manutenção e o fortalecimento do poder dados pela concentração de renda em nome de poucos e em detrimento da maioria da população continuam a ser uma das maiores mazelas a serem combatidas para uma vida substancialmente democrática, a qual tem a escola como instituição privilegiada.

\section{REFERÊNCIAS}

ADORNO, Theodor W. Educação e emancipação. Rio de Janeiro: Paz e Terra, 1995.

ADORNO, Theodor W. Teoría de la pseudocultura. In: ADORNO, Theodor W. Escritos sociológicos I. Madrid: Akal, 2004a. p. 86-113.

ADORNO, Theodor W. Cultura y administración. In: ADORNO, Theodor W. Escritos sociológicos I. Madrid: Akal, 2004b. p. 113-136.

ADORNO, Theodor W. ¿Capitalismo tardío o sociedad industrial?. In: ADORNO, Theodor W. Escritos sociológicos I. Madrid: Akal, 2004c. p. 330-344.

ADORNO, Theodor W. Reflexiones sobre la teoría de las clases. In: ADORNO, Theodor W. Escritos sociológicos I. Madrid: Akal, 2004d. p. 347-364.

ADORNO, Theodor W. Contribución al debate sobre "¿Capitalismo tardío o sociedad industrial?". In: ADORNO, Theodor W. Escritos sociológicos I. Madrid: Akal, 2004e. p. 536-543.

ADORNO, Theodor W. Sobre a relação entre sociologia e psicologia. In: ADORNO, Theodor W. Ensaios sobre psicologia social e psicanálise. São Paulo: Editora Unesp, 2015. p. 71-135.

ADORNO, Theodor W. Estudos sobre a personalidade autoritária. São Paulo: Editora Unesp, 2019.

ADORNO, Theodor W.; FRENKEL-BRUNSWIK, Else; LEVINSON, Daniel; SANFORD, Nevitt. The Authoritarian Personality. New York, NY: Harper and Row, 1950.

ANDERSON, Perry. Balanço do neoliberalismo. In: SADER, Emir; GENTILI, Pablo (org.). Pós-neoliberalismo: as políticas sociais e o Estado democrático. Rio de Janeiro: Paz e Terra, 1995. p. 9-23. 
ANTUNES, Débora Christina; ZUIN, Antonio Álvaro Soares. Do bullying ao preconceito: os desafios da barbárie à educação. Psicologia e Sociedade, São Paulo, v. 20, n. 1, p. 33-42, 2008.

BORDIEU, Pierre. La esencia del neoliberalismo. Revista Colombiana de Educación, Bogotá, Núm. 35, 1998. DOI:10.17227/01203916.5426.

BRESSER-PEREIRA, Luiz Carlos. Assalto ao Estado e ao mercado, neoliberalismo e teoria econômica. Estudos Avançados [online], São Paulo, v. 23, n. 66, p. 7-23, 2009. Disponível em: https:/www.scielo.br/j/ea/a/F8tmPL4Z7PBjDtnhzHV7hVm/ abstract/?lang=pt. Acesso em: 3 jun. 2021.

CROCHICK, José Leon; CROCHICK, Nicole. Bullying, preconceito e desempenho escolar: uma nova perspectiva. São Paulo: Benjamin Editorial, 2017. v. 1.

CROCHICK, José Leon. Preconceito e bullying: marcas da regressão psíquica socialmente induzida. Psicologia USP, São Paulo, v. 30, e190006, p. 1-11, 2019. Disponível em: http:// www.scielo.br/scielo.php?script=sci_arttext\&pid=S0103-65642019000100215\&lng= en\&nrm=iso. Acesso em: 18 abr. 2021. http://dx.doi.org/10.1590/0103-6564e190006.

FAVERO, Altair Alberto; CONSALTER, Evandro; TONIETO, Carina. A lógica do mercado e suas implicações nas políticas e processos de avaliação da educação superior. Educar em Revista, Curitiba, v. 36, e74384, p. 1-20, 2020. Disponível em: http://www. scielo.br/scielo.php?script=sci_arttext\&pid=S0104-40602020000100145\&lng=pt\&nrm =iso. Acesso em: 16 abr. 2021. https://doi.org/10.1590/0104-4060.74384.

FREUD, Sigmund. Três ensaios sobre a teoria da sexualidade. Rio de Janeiro: Imago, 1997.

FREUD, Sigmund. Mal-estar na civilização e outros trabalhos. São Paulo: Companhia das Letras, 2011.

GREEN, André. Narcisismo de vida, narcisismo de morte. São Paulo: Escuta, 1988.

HABERMAS, Jurgen. Técnica e ciência enquanto ideologia. In: BENJAMIN, Walter; HORKHEIMER, Max; ADORNO, Theodor W.; HABERMAS, Jurgen. Textos escolhidos. São Paulo: Abril, 1983. p. 313-343.

HARVEY, David. O neoliberalismo, história e implicações. São Paulo: Loyola, 2008.

HOBSBAWM, Eric. Era dos extremos: o breve século XX: 1914-1991. São Paulo: Companhia das Letras, 1995.

HORKHEIMER, Max; ADORNO, Theodor W. Temas básicos de sociologia. São Paulo: Cultrix, 1973.

HORKHEIMER, Max; ADORNO, Theodor W. Dialética do esclarecimento. Rio de Janeiro: Zahar, 1985. 
KORSCH, Karl. A luta dos trabalhadores contra o fascismo. A Terra é Redonda, São Paulo, 2020. Disponível em: https://aterraeredonda.com.br/a-luta-dos-trabalhadorescontra-o-fascismo/. Acesso em: 25 mar. 2020.

LASCH, Cristopher. A cultura do narcisismo: a vida americana numa era de esperanças em declínio. Tradução de Emani Pavaneli. Rio de Janeiro: Imago, 1983.

LUKÁCS, Georg. História e consciência de classe. São Paulo: Martins Fontes, 2018.

MARCUSE, Herbert. Eros e civilização. Rio de Janeiro: Zahar, 1981.

MARCUSE, Herbert. Ideologia da sociedade industrial. Rio de Janeiro: Zahar, 1982.

MARX, Karl. O capital: crítica da economia política. São Paulo: Difel, 1984.

PAULANI, Leda Maria. Neoliberalismo e individualismo. Economia e Sociedade, Campinas, v. 8, n. 2, p. 115-127, dez. 1999.

SILVA, Monica Ribeiro da. A BNCC da reforma do ensino médio: o resgate de um empoeirado discurso. Educação em Revista, Belo Horizonte, v. 34, e214130, p. 1-15, 2018. Disponível em: http://www.scielo.br/scielo.php?script=sci_arttext\&pid=S010246982018000100301\&lng=en\&nrm=iso. Acesso em: 16 abr. 2021. https://doi. org/10.1590/0102-4698214130.

TAFFAREL, Celi Nelza Zulke; BELTRÃO, José Arlen. Destruição de forças produtivas e o rebaixamento da formação da classe trabalhadora: o caso da reforma da BNCC do ensino médio. Germinal: Marxismo e Educação em Debate, Salvador, v. 11, n. 1, p. 103-115, abr. 2019.

WRIGHT MILLS, Charles. White Collar, The American Middle Classes. Oxford: Oxford University Press, 1951.

Texto recebido em $08 / 04 / 2021$.

Texto aprovado em 20/05/2021. 